\title{
Effect of a 25 ingredient sport drink on exercise performance and muscle oxygen extraction:
}

\section{a randomized controlled cross-over trial}

\author{
Hannes Gatterer ${ }^{1,2 *}$, Marc Philippe ${ }^{1,3}$, Hanno Fröhlich', Stefan Bachler ${ }^{1}$, Florian Mosbach ${ }^{1}$, Martin Burtscher \\ 1 Department of Sport Science, University Innsbruck, Innsbruck, Austria \\ 2 Institute of Mountain Emergency Medicine, EURAC Research, Bolzano, Italy \\ 3 Department of Sports Medicine, Institute of Sports Sciences, Justus-Liebig-University, Giessen, German \\ * Corresponding author: Hannes Gatterer, Institute of Mountain Emergency Medicine, EURAC Research, \\ Viale Druso 1, 39100 Bolzano, Italien, Tel.: +39 0471055 578, \\ Email: hannes.gatterer@eurac.edu
}

\section{ORIGINAL ARTICLE}

\section{Article History:}

Submitted 29th May 2017

Accepted 22 ${ }^{\text {nd }}$ October 2017

Published $27^{\text {th }}$ November 2017

Handling Editor:

Arno Schmidt-Trucksäss,

University of Basel, Switzerland

Editor-in-Chief:

Martin Kopp

University of Innsbruck, Austria

Reviewers:

Reviewer 1: anonymous

Reviewer 2: anonymous

\section{ABSTRACT}

Recently, a new sport drink containing a mixture of potential ergogenic substances was introduced to the market. Various athletes reported beneficial performance effects from the supplement, though without scientific evidence. The aim of this study was to investigate the effects of the sport drink on exercise performance. Nine sport students performed three test sessions including a cycle exercise tests to exhaustion, a leg strength test and a jump test. Each session was separated by 1 week. The first session was performed as a familiarization trial. In a random order, half of the participants performed the second session after consumption of the multi ingredient sport drink (MISD intake of 40g, 24 and $1 \mathrm{~h}$ before each test) and half after placebo ingestion (same amount). During the third session the conditions were reversed (cross-over setting). Near infrared spectroscopy analyses were performed on the vastus lateralis during the MISD and placebo cycling test. The sport drink compared to placebo, improved maximal power output ( $7 \mathrm{~W}, 95 \% \mathrm{Cl} 1.1-13.4)$, increased maximal lactate concentration ( $2.5 \mathrm{mmol} / \mathrm{l}, 95 \% \mathrm{Cl} 1.6-3.4)$, and power output at the individual threshold (Dmax) (6.1 $\mathrm{W}, 95 \% \mathrm{Cl} 1.9-10.3)$. Power output at the $4 \mathrm{mmol} / \mathrm{l}$ threshold was reduced $(9.0 \mathrm{~W}, 95 \% \mathrm{Cl}-17.4$ to -0.6$)$ during the MISD trial. Additionally, the sport drink led to a steeper tissue oxygenation index decrease (TOI, slope: $-0.02 \pm 0.01$ vs. $-0.03 \pm 0.01, p<0.005$ ) during the test. Leg strength and jump ability was not affected by the supplement. The sport drink slightly increased power output during an incremental exercise test. Due to the broad range of substances in the supplement and their different effects, the factors involved in the performance enhancement are speculative. Data show that factors other than muscle oxygen extraction (represented by TOI) are involved in the improved maximal power output.

Keywords:

sports nutrition - dietary supplements - ergogenic aid - power output - endurance

Citation:

H. Gatterer, M. Philippe, H. Fröhlich, S. Bachler, F. Mosbach, M. Burtscher (2017). Effect of a 25 ingredient sport drink on exercise performance and muscle oxygen extraction: a randomized controlled cross-over trial. Current Issues in Sport Science, 2:008. doi: 10.15203/CISS_2017.008 


\section{Introduction}

There exist various dietary supplements ascribed as having ergogenic effects. These substances include caffeine, bicarbonate, different proteins and carbohydrates, and antioxidants (Blomstrand, 2006; Cermak \& van Loon, 2013; Gatterer, Greilberger, Philippe, Faulhaber, Djukic, \& Burtscher, 2013; Graham, 2001; Kreider et al., 2010; Pesta, Angadi, Burtscher, \& Roberts, 2013). The mechanisms for performance improvements are as diverse as the supplements. For example, caffeine is an inhibitor of adenosine receptors, stimulates the secretion of adrenaline (epinephrine) (Graham, 2001), and thus, may act on the metabolism and on different tissues including the brain. Bicarbonate on the other hand, might improve high intensity exercise capacity by increasing buffer capacity (Kreider et al., 2010). Protein and carbohydrate ingestion enhances carbohydrate storage and protein synthesis (Kreider et al., 2010) and might act on perception of fatigue (i.e., central fatigue) (Cermak \& van Loon, 2013; Kreider et al., 2010). Lastly, antioxidant supplementation is thought to reduce oxidative stress, which was found to impair muscular contractile and mitochondrial function (Braakhuis \& Hopkins, 2015; Matuszczak et al., 2005; Ott, Gogvadze, Orrenius, \& Zhivotovsky, 2007; Reid, 2001, 2008).

Recently, a sport drink with 25 different ingredients was introduced to the market (compounds listed in Table 1) and was claimed to have performance enhancing effects. However, some substances, for example caffeine and carbonate, fail to reach doses suggested to be sufficient to improve performance (Close, Hamilton, Philp, Burke, \& Morton, 2016; Graham, 2001; Kreider et al., 2010). Conversely, it could be argued that combining low doses of different ergogenic aids may improve performance without the side effects associated with too high doses of isolated individual substances. For example, high doses of caffeine and carbonate may result in gastrointestinal discomfort, anxiety and restlessness (Astorino \& Roberson, 2010; Close et al., 2016). Additionally, it could be argued that different individuals may differently benefit from various substances even though no scientific data confirming such individual responses exist yet. This study aims to investigate whether short term ingestion of the 25 ingredient sport drink improves incremental exercise test outcome, jump ability and maximal isometric leg strength. These tests have been chosen as better test outcomes are related to better performance in various sports. For instance, good results in the incremental exercise test are linked to better cardiovascular fitness which is critical for endurance athletes. On the contrary good jump and strength outcome are related to good anaerobic performance which is critical for a variety of sports as for example skiing, soccer etc. Thus, enhanced performance in the selected test outcomes is highly desirable for both strength/power and endurance athletes.

\section{Methods}

\section{Participants}

Twelve male sport students (active in multi-sports) were recruited for the study and provided written informed consent for participation. Participants reported no acute or chronic diseases and none was on medication. Participants were advised not to use nutritional supplements besides the ones under investigation, nor to change nutritional habits and training practice during the study period. Nutritional intake was controlled with a $24 \mathrm{~h}$ dietary logbook before each test. Three participants dropped out during the study. One because of muscle soreness prior to testing, one because of excessive training during the study period (even though participants were advised not to change normal training practice during the study period) and one because of sleeplessness prior to the MISD trial (the participant never drinks caffeine, a compound of sport drink). Therefore, nine participants (age: $24 \pm 2$ year; weight: 75.6 \pm 7.4 $\mathrm{kg}$; height: $182.9 \pm 6.7 \mathrm{~cm}$; $\mathrm{VO}_{\text {peak }}: 3.8 \pm 0.3 \mathrm{l} / \mathrm{min}$ ) were included in the analyses. The study was carried out in conformity with the ethical standards of the Declaration of Helsinki and was approved by the Institutional Review Board of the Department of Sport Science at the University of Innsbruck. Parts of the data have been published in German language in the "Deutsche Zeitschrift für Sportmedizin" (Fröhlich, Gatterer, Philippe, Insam, Gröbner, \& Burtscher, 2017).

\section{Procedures}

The study was designed as a single blinded placebo controlled cross over trial. Each participant completed 3 exercise sessions separated by 1 week. The participants performed the tests at approximately the same time of day ( $\pm 2 \mathrm{~h}$ ), were advised to abstain from strenuous exercise at least $24 \mathrm{~h}$ prior to each test and from caffeine intake the day of testing. All sessions included a 10 min warm up period on a cycle ergometer, followed by a counter movement jump (CMJ), a maximal isometric leg strength test, and an incremental cycle test until exhaustion (for a more detailed description see below). The first session was a familiarization trial. During the second session half of the participants performed the tests after consumption of the sport drink and half after ingestion of a placebo drink. During the third session the conditions were reversed. The order of the MISD and placebo trial was randomized.

\section{Supplementation}

Participants ingested $40 \mathrm{~g}$ of the MISD or placebo powder solved in $500 \mathrm{ml}$ water twenty-four and $1 \mathrm{~h}$ before the respective test session. The first dose was administered to assess tolerance to the substances (prior to administration, participants were asked for known intolerance as well) and the second dose corresponded to the pre-exercise dose recommended by the manufacturer (BANOS s.r.o., Austria). The components of the 
sport drink are shown in Table 1. The placebo consisted of identical looking and tasting fluid, containing mainly erythritol (17.72 g), black currant juice powder (1 g) and citric acid (500 $\mathrm{mg}$ ) with no ergogenic effect.

Table 1: Components of the sport drink

\begin{tabular}{ll}
\hline Compounds & per $100 \mathrm{~g}$ \\
\hline Maltodextrin & $40.7 \mathrm{~g}$ \\
Fructose & $15 \mathrm{~g}$ \\
Glucose & $15 \mathrm{~g}$ \\
L-leucine & $2.5 \mathrm{~g}$ \\
L-valine & $1.3 \mathrm{~g}$ \\
L-isoleucine & $1.3 \mathrm{~g}$ \\
Potassium & $750.0 \mathrm{mg}$ \\
Resveratrol & $750.0 \mathrm{mg}$ \\
Sodium & $678.6 \mathrm{mg}$ \\
Carbonate & $484.6 \mathrm{mg}$ \\
Caffeine & $375.0 \mathrm{mg}$ \\
Taurine & $350.0 \mathrm{mg}$ \\
Calcium & $326.6 \mathrm{mg}$ \\
Ascorbate & $200.0 \mathrm{mg}$ \\
Magnesium & $150.0 \mathrm{mg}$ \\
Niacin & $22.5 \mathrm{mg}$ \\
Pantothenic Acid & $17.5 \mathrm{mg}$ \\
Vitamin E & $15.0 \mathrm{mg}$ \\
Zinc & $12.5 \mathrm{mg}$ \\
Pyridoxal & $2.5 \mathrm{mg}$ \\
Thiamine & $2.25 \mathrm{mg}$ \\
Folic acid & $225.0 \mu \mathrm{gg}$ \\
Selenium & $50.0 \mu \mathrm{g}$ \\
Cholecalciferol & $6.0 \mu \mathrm{g}$ \\
Vitamin B12 & $4.0 \mu \mathrm{g}$ \\
\hline & \\
\hline
\end{tabular}

\section{Performance tests and measurements}

The maximal isometric leg strength test was performed on an isometric leg tester (ILT, ISW, Austria) for each leg separately. Although, we have no data on the CV for ILT, the smallest CV for leg press power output was reported to be approximately $5.1 \%$ (Hopkins, Schabort, \& Hawley, 2001). Participants were fixed in a sitting position on the leg strength tester with a knee angle of $100^{\circ}$ and were advised to push maximally against a strength platform for 5 seconds. Three trials were performed with $10 \mathrm{sec}$ rest between trials. The trial with the highest strength output for each leg was noted. The mean of the highest values of both legs was taken for analyses.

The CMJ was performed on a Kistler force platform (Kistler, Switzerland). The CMJ has been shown to be a suitable test to determine muscle power in athletes (Patterson, Raschner, \& Platzer, 2009). In our laboratory intraclass correlation coefficients between $r=0.944$ and $r=0.981$ were reported (Patterson et al., 2009) and the smallest CV for jump testing in general is 1.8\% (Hopkins et al., 2001). The test was performed 2-footed, with participants instructed to place their hands on their hips to eliminate the influence of the arm-swing impulse. The jump was started from an erect position. When given a verbal command, the participant made the downward countermovement to his preferred position and then immediately jumped vertically for maximum height. Three maximal CMJs were recorded, and the trial with the best jump height $(\mathrm{cm})$ and force production $(\mathrm{N} / \mathrm{kg}$ ) were used for further analysis (Gatterer, Schenk, et al., 2013).

The incremental cycle tests were performed on the Cyclus II ergometer (RBM, Germany). The starting workload was 100 $\mathrm{W}$, followed by $50 \mathrm{~W}$ increments every 3 min until exhaustion. Peak power output was defined as the last completed work rate plus the fraction of time spent in the final uncompleted work rate multiplied by $50 \mathrm{~W}$. During the last 30 seconds of each stage and at 3, 10 and $20 \mathrm{~min}$ after the test, capillary blood samples were taken from the earlobe for the determination of the lactate concentration ([La]) (Biosen C-line, EKF, Germany). To account for possible effects of the substances on the [La] (e.g., caffeine), which might mask performance changes when using fixed lactate thresholds, the lactate threshold was established by two different methods. One lactate threshold was determined according to the $D_{\max }$ method. The principle of the method is to create a linear regression line between the blood lactate concentrations at the beginning and the end of an incremental exercise test, as well as a third-order polynomial regression line that represents the blood lactate kinetics during exercise. The point of the maximum distance between the polynomial curve and the straight line observed is defined as the lactate threshold (Cheng et al., 1992; Zhou \& Weston, 1997). The second lactate threshold was considered as the power output at a fixed [La] of $4 \mathrm{mmol} / \mathrm{l}$.

In addition to the evaluation of [La], gas analyses (Oxycon mobile, CareFusion, Germany) were performed over the entire test duration to establish the peak oxygen uptake $\left(\mathrm{VO}_{\text {peak }}\right)$ and the ventilatory threshold (VT). The VT was defined as the first systematic increase in ventilatory equivalents of oxygen (VE/ VO2) without a concomitant increase in the ventilatory equivalent of CO2 (VE/VCO2) (Amann, Subudhi, \& Foster, 2006). Heart rate was continuously monitored with a Polar chest belt connected to the spiroergometric device and data were averaged over $5 \mathrm{~s}$ periods for further analyses. Moreover, during the two cross over test sessions (test 2 and 3), near infrared spectroscopy (NIRS) measurements (Niro-200, Hamamatsu Photonics K.K., Japan) were performed. The NIRS electrodes were placed longitudinally over the distal part of the belly of the musculus vastus lateralis. Near infrared spectroscopy provides the tissue oxygenation index (TOI), which is the ratio of oxygenated to total tissue haemoglobin. Near infrared spectroscopy reflects changes in tissue $\mathrm{O} 2$ saturation relative to rest and was shown to provide information on oxygen availability, and rate of oxygen utilization, therefore, indicating crude alterations in tissue oxygen extraction (Boushel, Langberg, Olesen, Gonzales-Alonzo, Bülow, \& Kjaer, 2001). The slope, calculated by linear regression and indicative for the $\mathrm{O} 2$ extraction, was taken for analysis. The slope was plotted a) over the whole test time, b) from the 
start until the end of the 150-watt step, c) until reaching the $D_{\max }$ threshold and d) until reaching the $4 \mathrm{mmol} / \mathrm{l}$ threshold.

\section{Statistical Analyses}

Data were analysed using IBM SPSS Statistics 21. An analysis of variance (ANOVA) with repeated measurement design was used to identify changes in $\mathrm{VO}_{\text {peak, }}$ maximal power output $\left(P_{\max }\right)$, and maximal lactate concentration ([La $]_{\max }$ ) during the 3 week testing period (familiarization and training effect). If ANOVA revealed significant differences, post hoc t-tests with Bonferroni correction was used to localize the changes. Additionally, data were analyzed for possible carry over effects according to Wellek et al. (Wellek \& Blettner, 2012). Changes from the MISD and placebo trial were assessed by paired student $t-$ Tests. Effect size (ES, Cohen's d) was calculated for differences between conditions. Pearson correlation analyses were used to calculate associations between performance parameters, [La] and TOI values. Delta values $(\Delta)$ were calculated as post values minus pre values. Technical problems during some tests resulted in data loss leading to slightly differing sample sizes. Data are presented as means $\pm \mathrm{SD}$ and/or in the case of the performance parameters as mean changes $\pm 95 \% \mathrm{Cl}$ (confidence interval). The level of significance was set at $p \leq 0.05$

\section{Results}

The $24 \mathrm{~h}$ dietary logbook revealed no differences in nutritional intake before the test sessions (carbohydrate intake: $305 \pm 121$ vs. $355 \pm 146 \mathrm{~g}$, protein intake: $106 \pm 41$ vs. $98 \pm 33$ and fat intake: $110.2 \pm 58.9$ vs. $120.3 \pm 55.2 \mathrm{~g}$ for the placebo and MISD trial, respectively, $p>0.05$ ). An analysis of variance with repeated measurement design revealed small increases in $P_{\max }$ in the course of the 3 week testing period $\left(P_{\max }\right.$ differed from the familiarization session to test 2 , no differences were found between test 1 and 2 , which represented the crossover trial; post hoc test). During the cross over setting no carry over effect was present.

Outcomes of all performance parameters are depicted in Table 2. The sport drink improved $P_{\max }$ increased $H R_{\text {peak }}$ $[\mathrm{La}]_{\max }$ and power output at the $\mathrm{D}_{\max }$ threshold $\left(P-\mathrm{D}_{\max }\right) \mathrm{com}$ pared to the placebo trial $(p<0.05)$. On the contrary, power output at the $4 \mathrm{mmol}$ threshold $(\mathrm{P}-4 \mathrm{mmol} / \mathrm{l})$ was reduced $(p<0.05)$ during the MISD trial (Table 2). Additionally, the sport drink lead to a steeper TOI decrease during the entire test $(-0.018 \pm 0.008$ vs. $-0.026 \pm 0.007, \mathrm{p}<0.05)$ and until reaching $D_{\max }$ $(-0.022 \pm 0.012$ vs. $-0.030 \pm 0.011, p<0.05)$ and the $4 \mathrm{mmol}$ threshold $(-0.022 \pm 0.012$ vs. $-0.032 \pm 0.013, p<0.05)$. Lactate removal after the test was not influenced by the supplement $(-2.5 \pm 0.9$ vs. $-2.2 \pm 1.4 \mathrm{mmol} / \mathrm{l}$ after $10 \mathrm{~min}$ and $-3.6 \pm 1.3$ vs. $-3.6 \pm 0.9$ after 20 min, $p>0.05$, for the MISD and placebo trial respectively).

Table 2: Performance parameters in the course of the cross over trial

\begin{tabular}{|c|c|c|c|c|c|c|c|c|}
\hline & \multirow[b]{2}{*}{$\mathrm{n}$} & \multicolumn{3}{|c|}{ Consecutive test order } & \multicolumn{4}{|c|}{ Cross over design } \\
\hline & & Familiarization trial & Test 1 & Test 2 & Placebo trial & MISD trial & $\begin{array}{c}\text { Mean changes } \\
\qquad(95 \% \mathrm{Cl})\end{array}$ & ES \\
\hline Body weight $(\mathrm{kg})$ & 9 & $75.6 \pm 7.4$ & $75.6 \pm 7.1$ & $75.7 \pm 7.4$ & $75.6 \pm 7.2$ & $75.6 \pm 7.3$ & - & - \\
\hline$P_{\max }(W)$ & 9 & $286.8 \pm 23.1$ & $293.6 \pm 24.4$ & $297.2 \pm 30.8^{\#}$ & $291.8 \pm 27.3$ & $299.0 \pm 27.9^{*}$ & $7.2(1.1-13.4)$ & 0.90 \\
\hline $\mathrm{VO}_{2 \text { peak }}(\mathrm{ml} / \mathrm{min})$ & 7 & $3774 \pm 337$ & $3796 \pm 254$ & $3895 \pm 376$ & $3826 \pm 276$ & $3864 \pm 367$ & $38(-143-220)$ & 0.12 \\
\hline $\mathrm{HR}_{\text {peak }}(\mathrm{b} / \mathrm{min})$ & 9 & $188 \pm 7$ & $186 \pm 6$ & $185 \pm 8$ & $183 \pm 7$ & $187 \pm 6^{*}$ & $3.7(1.4-5.9)$ & 1.30 \\
\hline$[\mathrm{La}]_{\max }(\mathrm{mmol} / \mathrm{l})$ & 8 & $11.4 \pm 1.9$ & $11.9 \pm 3.0$ & $12.4 \pm 2.0$ & $10.9 \pm 2.1$ & $13.4 \pm 2.3^{*}$ & $2.5(1.6-3.4)$ & 2.48 \\
\hline $\mathrm{VO}_{2}-150 \mathrm{~W}(\mathrm{ml} / \mathrm{min})$ & 9 & $2231 \pm 162$ & $2162 \pm 168$ & $2214 \pm 128$ & $2151 \pm 166$ & $2225 \pm 123$ & $74(-30-179)$ & 0.54 \\
\hline $\mathrm{HR}_{150 \mathrm{w}}(\mathrm{b} / \mathrm{min})$ & 9 & $139 \pm 11$ & $137 \pm 10$ & $134 \pm 9$ & $135 \pm 9$ & $136 \pm 11$ & $1.4(-3.6-6.5)$ & 0.15 \\
\hline P-VT (W) & 8 & $161.0 \pm 11.0$ & $155.9 \pm 13.9$ & $162.9 \pm 20.9$ & $160.9 \pm 21.9$ & $157.9 \pm 13.1$ & $-3.0(-16-11)$ & 0.17 \\
\hline $\mathrm{P}-4 \mathrm{mmol} / \mathrm{l}(\mathrm{W})$ & 8 & $225.1 \pm 32.4$ & $223.5 \pm 37.9$ & $225.5 \pm 26.5$ & $229.0 \pm 31.8$ & $220.0 \pm 32.9^{*}$ & $-9(-17.4--0.6)$ & 0.63 \\
\hline $\mathrm{HR}-4 \mathrm{mmol} / \mathrm{l}(\mathrm{b} / \mathrm{min})$ & 8 & $169 \pm 10$ & $165 \pm 5$ & $163 \pm 6$ & $165 \pm 5$ & $163 \pm 6$ & $-2(-4-0)$ & 0.97 \\
\hline$P-D_{\max }(W)$ & 8 & $217.4 \pm 18.9$ & $221.5 \pm 20.2$ & $224.6 \pm 25.0$ & $220.0 \pm 21.3$ & $226.1 \pm 23.7^{*}$ & $6.1(1.9-10.3)$ & 1.22 \\
\hline$H R-D_{\max }(b / m i n)$ & 8 & $166 \pm 9$ & $163 \pm 6$ & $163 \pm 8$ & $161 \pm 7$ & $165 \pm 7^{*}$ & $3(1.2-5.6)$ & 1.3 \\
\hline Jump height $(\mathrm{cm})$ & 9 & $35.8 \pm 5.8$ & $35.1 \pm 7.4$ & $35.5 \pm 6.6$ & $35.0 \pm 7.3$ & $35.7 \pm 6.6$ & $0.8(-0.7-2.2)$ & 0.37 \\
\hline Leg strength $(\mathrm{N} / \mathrm{kg})$ & 9 & $20.0 \pm 2.8$ & $19.4 \pm 3.3$ & $19.3 \pm 3.3$ & $19.6 \pm 3.5$ & $19.1 \pm 3.0$ & $-0.5(-1.0-0.0)$ & 0.75 \\
\hline
\end{tabular}

Maximal power output, $\mathrm{P}_{\text {max }}$ peak oxygen uptake, $\mathrm{VO}_{2 \text { peak }}$ peak heart rate, $\mathrm{HR}_{\text {peak }}$ maximal lactate concentration, $[\mathrm{La}]_{\text {max }}$ oxygen uptake at a power output of $150 \mathrm{~W}$ VO2-150W; power output at the ventilatory threshold, P-VT; power output at the $4 \mathrm{mmol} / \mathrm{l}$ lactate threshold, $\mathrm{P}-4 \mathrm{mmol}$; power output at the $\mathrm{D}_{\max }$ threshold, $\mathrm{P}-\mathrm{D}_{\max }$ Cohens d effect size, ES

Values are presented as means \pm SD except for mean changes where $95 \% \mathrm{Cl}$ (confidence interval) was used.

* indicates significant differences when compared to the placebo trial

\# indicates significant differences when compared to the familiarization trial 
No changes in jump height and leg strength were found between the MISD and placebo trial (Table 2). Changes in $\mathrm{P}_{\max }\left(\Delta \mathrm{P}_{\max }\right)$ of the cycle tests were positively associated with changes in $[\mathrm{La}]_{\max }\left(\Delta[\mathrm{La}]_{\max }\right), \mathrm{r}=0.801, \mathrm{p}=0.017$. No associations were found between submaximal and maximal performance changes or between $\mathrm{TOI}$ and performance changes.

\section{Discussion}

The main findings of the present investigation were that the 25 ingredient sport drink increased $\mathrm{P}_{\max ,}, \mathrm{HR}_{\text {peak }}[\mathrm{La}]_{\max }$ and $\mathrm{P}-\mathrm{D}_{\max ,}$ and decreased $\mathrm{P}-4 \mathrm{mmol} / \mathrm{l}$ during the incremental cycle test, without affecting $\mathrm{VO}_{2 \text { peak. }}$. The $\mathrm{P}_{\max }$ improvement was associated with the increase of [La $]_{\max }$. Furthermore, TOI decrease was steeper during the MISD trial, indicating faster $\mathrm{O} 2$ extraction, however, without effect on performance parameters. Additionally, jump performance and leg strength were not affected.

The newly developed sport drink is a dietary supplement that contains 25 different ingredients. Due to possible combined effects of these substances, it was speculated that the sport drink might have a performance enhancing effect, even though some individual doses of ingredients might appear low. In accordance, small but significant improvements in power output during an incremental exercise test were observed. Due to the variety of substances in the supplement the exact mechanisms leading to performance changes can only be speculative. Thus, in the following discussion, some individual substances that most likely might have contributed to the enhanced performance will be addressed in detail whereas a more general overview will be given to the effects of other substances.

From the substances included in the supplement, the literature shows that caffeine may have an actual ergogenic effect. The mechanisms by which caffeine influences performance could be linked to its central nervous system (CNS) stimulating effect. Stimulation of the CNS might influence sympathetic activity, motor recruitment, perception of fatigue (Graham, 2001) and thus, performance. Additionally, there is some evidence that high caffeine doses may also improve carbohydrate absorption and oxidation (Yeo, Jentjens, Wallis, \& Jeukendrup, 2005). Further hypothetical mechanisms that were only shown when using high caffeine doses and/or ex vivo (James, Wilson, \& Askew, 2004; Rosser, Walsh, \& Hogan, 2009), include alterations in electrolyte homeostasis. For example, caffeine has been shown to stimulate muscle sodium/potassium ATPase, either directly or indirectly, by increasing adrenalin concentration (Lindinger, Graham, \& Spriet, 1993), thus reducing potassium loss during contractions and conserving motor unit activation (Graham, 2001). Furthermore, caffeine can alter calcium exchange by the sarcoplasmic reticulum, which might impact on performance by enhancing excitation-contraction coupling (Graham, 2001). However, a caffeine dose of $10 \mathrm{mg} / \mathrm{kg}$ may not easily translate into practical application. On the other hand, it was reported that lower caffeine doses (2-3 mg/kg BM) may also be effective in improving performance (Graham, 2001) and this inde- pendently of an enhanced carbohydrate use (Hulston \& Jeukendrup, 2008) and of the caffeine concentration in the blood during endurance exercise (Skinner, Jenkins, Taaffe, Leveritt, \& Coombes, 2013). However, it should also be mentioned that controversial reports exist showing no additional effect (Dodd, Brooks, Powers, \& Tulley, 1991). Moreover, it was reported that caffeine increases [La] (Anselme, Collomp, Mercier, Ahmaïdi, \& Prefaut, 1992; Graham, 2001). In the present investigation, such increases in [La] might be responsible for the higher [La $]_{\max }$ and the reduced power output at the fixed $4 \mathrm{mmol} / \mathrm{l}$ threshold by a simple upward shift of the lactate curve. In contrast, the $D_{\max }$ threshold, representing an individual threshold that is not influenced by the absolute [La] but rather by the shape of the lactate curve, should not be influenced by this effect.

In addition to caffeine, the different carbohydrates within the sport drink might have also affected energy provision (Cermak \& van Loon, 2013) and [La] (Jentjens et al., 2006) and as a consequence the fixed $4 \mathrm{mmol} / \mathrm{l}$ lactate threshold (MillardStafford, Brown, \& Snow, 2010). Of course, the higher power output achieved during the MISD trial, possibly due to CNS effects, might as well be responsible for the higher $[\mathrm{La}]_{\max }$. Accordingly, a strong correlation was found between $\Delta \mathrm{P}_{\max }$ and $\Delta[\mathrm{La}]_{\max }(\mathrm{r}=0.801, \mathrm{p}<0.05)$.

Carbonate supplementation might additionally have influenced $P_{\max }$ and [La] in the present study. During high intensity exercise, hydrogen ions accumulate which are buffered by bicarbonate ions (Kreider et al., 2010). Increasing the buffer capacity by ingestion of carbonate has been shown to improve short term performance (Kreider et al., 2010). Additionally, zinc, a further component of the sport drink, might enhance this effect by increasing carbonic anhydrase activity (Lukaski, 2005). Beside caffeine, carbohydrates, carbonate and zinc, the sport drink contains many other possible performance enhancing substances (Table 1) whose mode of actions might have additionally contributed to the present findings. For example, many antioxidants are included, which might impact performance by reducing the detrimental effect of oxidative stress on muscular contractile function (Reid, 2001, 2008). Additionally, different types of amino acids (i.e., branched chain amino acids) are parts of the sport drink with possible effects on central fatigue, which in turn may improve exercise performance (Kreider et al., 2010).

An interesting finding of the current study is linked to the NIRS outcomes. The sport drink steepened the slope of the TOI index, indicative of increased oxygen extraction (Gatterer, Greilberger, et al., 2013). However, this enhanced $\mathrm{O} 2$ extraction was not related to any of the established performance parameters. Theoretically, it seems appropriate to speculate that an improved $\mathrm{O} 2$ extraction might lead to a delayed lactate accumulation, and thus improve the lactate threshold. With respect to the $D_{\max }$ threshold, representing an individual threshold that is not influenced by the absolute [La] but rather by the shape of the lactate curve, this assumption was confirmed. On the contrary, power output at the $4 \mathrm{mmol} / \mathrm{l}$ lactate threshold was lower after ingesting the sport drink. As mentioned above, [La] might 
have been increased due to the effect of caffeine, leading to this effect.

\section{Methodological considerations and study limitation}

In addition to the constraints mentioned before, some further limitations have to be acknowledged. Three participants had to be excluded from analyses (reasons mentioned in the method section) reducing the statistical power of the study. Nonetheless, the sample size was still appropriate to reveal significant effects of the MISD (due to the large effect size, Table 1). Additionally, the number of subjects is comparable to various studies in the field, which are summarized in the reviews of Kreider and coworkers (Kreider et al., 2010) and Graham (Graham, 2001). In this regard, it was noted that one participant was not habituated to caffeine and experienced a side effect (sleeplessness) because of the sport drink. The possibility of such side effects need to be considered when working with athletes. Additionally, due to technical problems, two data sets of the gas analyses and one of the lactate analyses were not available. Nonetheless, the loss of these data should not exceedingly have influenced outcomes. A further weakness of the study is related to the various substances included in the sport drink. Notably, the effect of each individual substance was not assessed but only the combination of all ingredients on exercise performance was appraised. Additionally, doses and duration of supplementation differs to some extent from cited studies, thus this also needs to be considered when interpreting present results. Furthermore, it has to be mentioned that in the current study, a graded exercise test to exhaustion was performed to evaluate cardiovascular fitness. Further studies should establish the effect of the sport drink on competition-like endurance events (e.g., time trial test). Lastly, habituation (i.e., learning effects) and training effects during the study period may impact outcomes of dietary supplementation studies. Accordingly, ANOVA revealed that during the 3 week period, power output slightly increased, reaching statistical significance from the familiarization trial to test 2 (Table 2). Nonetheless, such an effect was not present between test 1 and test 2 which represents the cross over setting. Thus, we are confident that due to the familiarization session and the cross over design this error should be negligible in the present investigation.

In conclusion, the present study showed that ingestion of the 25 ingredient sport drink before incremental cycle exercise testing increased peak power output and power output at the individual lactate threshold. Furthermore maximal lactate concentration and peak heart rate was increased whereas power output at the $4 \mathrm{mmol} / \mathrm{l}$ lactate threshold was reduced. Furthermore, oxygen extraction seems to be enhanced without effect on exercise performance parameters. It appears reasonable to speculate that different athletes may benefit differently from the various substances and that central and peripheral factors might be responsible for the observed performance improvements. Further studies are needed to establish the exact mechanisms for potential performance improvements as well as the athletes group that might profit the most along with the right doses and timing of supplementation before training or competition.

\section{Acknowledgements}

We would like to thank Insahm K. and Gröbner F. for their help in data collection.

\section{Funding}

The authors have no funding or support to report.

\section{Competing Interests}

The supplement was sponsored by Dr. Baumgartl. The founding sponsors had no role in the design of the study, in the collection, analyses or interpretation of data, in the writing of the manuscript, and in the decision to publish the results. Parts of the data have been presented at the ECSS Congress in Vienna and have been published in German language in the "Deutsche Zeitschrift für Sportmedizin":

Fröhlich, H., Gatterer, H., Philippe, M., Insam, K., Gröbner, F., \& Burtscher, M. (2017): Effekte ergogener Substanzen eines Sportgetränks auf die Ausdauerleistung - eine randomisierte Cross-Over-Studie. Deutsche Zeitschrift für Sportmedizin, 68, 14-19. doi:10.5960/dzsm.2016.253.

\section{Data Availability Statement}

All relevant data are within the paper.

\section{References}

Amann, M., Subudhi, A. W., \& Foster, C. (2006). Predictive validity of ventilatory and lactate thresholds for cycling time trial performance. Scandinavian Journal of Medicine \& Science in Sports, 16(1), 27-34. doi:10.1111/j.1600-0838.2004.00424.x

Anselme, F., Collomp, K., Mercier, B., Ahmaïdi, S., \& Prefaut, C. (1992). Caffeine increases maximal anaerobic power and blood lactate concentration. European Journal of Applied Physiology and Occupational Physiology, 65(2), 188-191.

Astorino, T. A., \& Roberson, D. W. (2010). Efficacy of acute caffeine ingestion for short-term high-intensity exercise performance: a systematic review. The Journal of Strength \& Conditioning Research, 24(1), 257-265. doi:10.1519/ JSC.0b013e3181c1f88a

Blomstrand, E. (2006). A role for branched-chain amino acids in reducing central fatigue. Journal of Nutrition, 136(2), 544S-547S. 
Boushel, R., Langberg, H., Olesen, J., Gonzales-Alonzo, J., Bülow, J., \& Kjaer, M. (2001). Monitoring tissue oxygen availability with near infrared spectroscopy (NIRS) in health and disease. Scandinavian Journal of Medicine \& Science in Sports, 11(4), 213-222.

Braakhuis, A. J., \& Hopkins, W. G. (2015). Impact of Dietary Antioxidants on Sport Performance: A Review. Sports Medicine, 45(7), 939-955. doi:10.1007/s40279-015-0323-x

Cermak, N. M., \& van Loon, L. J. (2013). The use of carbohydrates during exercise as an ergogenic aid. Sports Medicine, 43(11), 1139-1155. doi:10.1007/s40279-013-0079-0

Cheng, B., Kuipers, H., Snyder, A. C., Keizer, H. A., Jeukendrup, A., \& Hesselink, M. (1992). A new approach for the determination of ventilatory and lactate thresholds. International Journal of Sports Medicine, 13(7), 518-522. doi:10.1055/s-2007-1021309

Close, G. L., Hamilton, D. L., Philp, A., Burke, L. M., \& Morton, J. P. (2016). New strategies in sport nutrition to increase exercise performance. Free Radical Biology \& Medicine, 98, 144-158. doi:10.1016/j.freeradbiomed.2016.01.016

Dodd, S. L., Brooks, E., Powers, S. K., \& Tulley, R. (1991). The effects of caffeine on graded exercise performance in caffeine naive versus habituated subjects. European Journal of Applied Physiology and Occupational Physiology, 62(6), 424-429.

Fröhlich, H., Gatterer, H., Philippe, M., Insam, K., Gröbner, F., \& Burtscher, M. (2017). Effekte ergogener Substanzen eines Sportgetränks auf die Ausdauerleistung - eine randomisierte Cross-Over-Studie. Deutsche Zeitschrift für Sportmedizin, 68, 14-19. doi:10.5960/dzsm.2016.253.

Gatterer, H., Greilberger, J., Philippe, M., Faulhaber, M., Djukic, R., \& Burtscher, M. (2013). Short-Term Supplementation with Alpha-Ketoglutaric Acid and 5-Hydroxymethylfurfural Does not Prevent the Hypoxia Induced Decrease of Exercise Performance Despite Attenuation of Oxidative Stress. International Journal of Sports Medicine, 34(1), 1-7. doi:10.1055/s-0032-1312584

Gatterer, H., Schenk, K., Wille, M., Raschner, C., Faulhaber, M., Ferrari, M., \& Burtscher, M. (2013). Race performance and exercise intensity of male amateur mountain runners during a multistage mountain marathon competition are not dependent on muscle strength loss or cardiorespiratory fitness. The Journal of Strength \& Conditioning Research, 27(8), 2149-2156. doi:10.1519/JSC.0b013e318279f817

Graham, T. E. (2001). Caffeine and exercise: metabolism, endurance and performance. Sports Medicine, 31(11), 785807.

Hopkins, W. G., Schabort, E. J., \& Hawley, J. A. (2001). Reliability of power in physical performance tests. Sports Medicine, 31(3), 211-234.

Hulston, C. J., \& Jeukendrup, A. E. (2008). Substrate metabolism and exercise performance with caffeine and carbohydrate intake. Medicine and Science in Sports and Exercise, 40(12), 2096-2104. doi:10.1249/MSS.0b013e318182a9c7
James, R. S., Wilson, R. S., \& Askew, G. N. (2004). Effects of caffeine on mouse skeletal muscle power output during recovery from fatigue. Journal of Applied Physiology (1985), 96(2), 545-552. doi:10.1152/japplphysiol.00696.2003

Kreider, R. B., Wilborn, C. D., Taylor, L., Campbell, B., Almada, A. L., Collins, R., ... Antonio, J. (2010). ISSN exercise \& sport nutrition review: research \& recommendations. Journal of the International Society of Sports Nutrition, 7, 7. doi:10.1186/1550-2783-7-7

Lindinger, M. I., Graham, T. E., \& Spriet, L. L. (1993). Caffeine attenuates the exercise-induced increase in plasma $[\mathrm{K}+]$ in humans. Journal of Applied Physiology (1985), 74(3), 11491155.

Lukaski, H. C. (2005). Low dietary zinc decreases erythrocyte carbonic anhydrase activities and impairs cardiorespiratory function in men during exercise. The American Journal of Clinical Nutrition, 81(5), 1045-1051.

Matuszczak, Y., Farid, M., Jones, J., Lansdowne, S., Smith, M. A., Taylor, A. A., \& Reid, M. B. (2005). Effects of N-acetylcysteine on glutathione oxidation and fatigue during handgrip exercise. Muscle \& Nerve, 32(5), 633-638. doi:10.1002/ mus.20385

Millard-Stafford, M. L., Brown, M. B., \& Snow, T. K. (2010). Acute carbohydrate ingestion affects lactate response in highly trained swimmers. International Journal of Sports Physiology and Performance, 5(1), 42-54.

Ott, M., Gogvadze, V., Orrenius, S., \& Zhivotovsky, B. (2007). Mitochondria, oxidative stress and cell death. Apoptosis, 12(5), 913-922. doi:10.1007/s10495-007-0756-2

Patterson, C., Raschner, C., \& Platzer, H. P. (2009). Power variables and bilateral force differences during unloaded and loaded squat jumps in high performance alpine ski racers. The Journal of Strength \& Conditioning Research, 23(3), 779-787. doi:10.1519/JSC.0b013e3181a2d7b3

Pesta, D. H., Angadi, S. S., Burtscher, M., \& Roberts, C. K. (2013). The effects of caffeine, nicotine, ethanol, and tetrahydrocannabinol on exercise performance. Nutrition \& Metabolism (Lond), 10(1), 71. doi:10.1186/1743-7075-10-71

Reid, M. B. (2001). Invited Review: redox modulation of skeletal muscle contraction: what we know and what we don't. Journal of Applied Physiology (1985), 90(2), 724-731.

Reid, M. B. (2008). Free radicals and muscle fatigue: Of ROS, canaries, and the IOC. Free Radical Biology \& Medicine, 44(2), 169-179. doi:10.1016/j.freeradbiomed.2007.03.002

Rosser, J. I., Walsh, B., \& Hogan, M. C. (2009). Effect of physiological levels of caffeine on $\mathrm{Ca} 2+$ handling and fatigue development in Xenopus isolated single myofibers. American Journal of Physiology. Regulatory, Integrative and Comperative Physiology, 296(5), R1512-1517. doi:10.1152/ ajpregu.90901.2008

Skinner, T. L., Jenkins, D. G., Taaffe, D. R., Leveritt, M. D., \& Coombes, J. S. (2013). Coinciding exercise with peak serum caffeine does not improve cycling performance. Journal of Science and Medicine in Sport, 16(1), 54-59. doi:10.1016/j. jsams.2012.04.004 
Wellek, S., \&Blettner, M. (2012). On the proper use of the crossover design in clinical trials: part 18 of a series on evaluation of scientific publications. Deutsches Ärzteblatt International, 109(15), 276-281. doi:10.3238/arztebl.2012.0276

Yeo, S. E., Jentjens, R. L., Wallis, G. A., \& Jeukendrup, A. E. (2005). Caffeine increases exogenous carbohydrate oxidation during exercise. Journal of Applied Physiology (1985), 99(3), 844-850. doi:10.1152/japplphysiol.00170.2005

Zhou, S., \& Weston, S. B. (1997). Reliability of using the D-max method to define physiological responses to incremental exercise testing. Physiological Measurement, 18(2), 145-154. 